\title{
Landscape renewal of urban public space under the concept of sustainable development: a case study of Guilin city
}

\author{
Fang Zhao ${ }^{1}$, Yanni Lai ${ }^{1}$, Qin $\mathrm{Du}^{1, *}$, Xuefang Xie ${ }^{1}$, Qiutong Chen ${ }^{1}$, Ziliu Qin ${ }^{1}$ \\ ${ }^{1}$ College of Tourism\&Landscape Architecture, Guilin University of Technology, Guilin 541006, China
}

\begin{abstract}
With the theory of "sustainable development" as the theoretical support, the public space landscape of Guilin City is taken as the research object, and from the perspective of landscape architecture, the public space landscape and the non-sustainability issues are deeply analyzed.Guilin city has been deeply investigated and studied.According to various types of public space landscape,five problems are concluded:landscape space problem,landscape energy consumption problem,landscape greening and planting problem,landscape rainwater resources digestion and utilization problem and landscape pollution reduction and noise reduction problem. The smooth solution of these five problems can promote the improvement of the urban environment and create sustainable urban public space.
\end{abstract}

\section{Sustainable Regeneration of Landscape}

\subsection{Concept of Landscape Sustainable Regeneration}

The idea of sustainable regeneration of the landscape is to apply the idea of sustainable development in urban design.Through the idea of sustainable landscape regeneration to design urban landscape,landscape can be regarded as a recycling energy source to provide energy and transform waste,not just in the general sense of plant greening.Landscape sustainable regeneration is also a renewal of the existing landscape,making it have the ability of recycling and regeneration, and forming a complete landscape system.

\subsection{Goal of Urban Public Space Landscape Regeneration under the Concept of Sustainable Development}

In the book Sustainable Urban Design,the traditional concept of city far away from nature is described as paying attention to the social and economic benefits of the city, ignoring the non-sustainable imbalance of the urban environment ${ }^{[1]}$.Traditional cities divide the relationship between man and nature,which are bound to be unsustainable.Landscape sustainable construction is not only a link between man and nature,but also a comprehensive and complex system.In the process of urban landscape construction,we should take the concept of sustainable development as the guide, integrate various resources, and make the artificial landscape sustainable.

Urban public space landscape regeneration is in an imperfect state in urban construction,we should make it as perfect as possible. The city is not a single object,but a complex and changeable system,which includes the harmony and unity of economy,culture,society, environment and resources.Sustainability design at the overall environmental level includes reducing dependence on fossil fuels in design,building sustainable communities,utilizing sustainable water cycle systems, and increasing the use of new energy sources ${ }^{[2]}$.The specific landscape objectives of urban public space landscape regeneration include the formation of public space landscape with productivity,low energy consumption,improving urban problems and improving utilization ratio.

\section{Principles and Strategies of Sustainable Renewal Design of Public Space Landscape}

\subsection{Design Principles}

In order to solve many problems of public space landscape,we put forward five principles from the aspects of landscape space,landscape energy consumption, landscape plants, water recycling, pollution reduction and noise reduction.

(1) We need to develop sustainable complex public space landscape.It includes utilizing urban roof space,elevation space and street corner space to optimize the spatial function.

(2) We must reduce landscape energy consumption.Including the use of new energy and new environmental landscape materials,building energy-saving landscape and recycling of old things.

(3) We use native plant materials.Local plants were

\footnotetext{
* Corresponding author: 80168391@qq.com
} 
selected as the main landscape plants, and the plants with high oxygen release,strong climate adaptability and high survival rate were selected again.

(4) Rainwater circulation and utilization are carried out.It includes utilizing permeable paving materials to infiltrate rainwater in urban public space and utilizing plant soft space to divert,slow release and collect rainwater,so as to realize the reuse of urban rainwater ${ }^{[3]}$.

(5) Landscape is used to reduce pollution and noise.It includes the use of plant materials to form isolation space,absorb air pollution,block noise and light pollution sources.

\subsection{Design Strategy}

Six design strategies are put forward from the aspects of landscape space, landscape energy consumption, landscape plants and water recycling, as well as pollution reduction and noise reduction.

(1)The development of landscape space. Including the use of urban corner space,roof space and underground space.

(2)We muse create new energy landscape.Including the creation of new energy generation landscape, the use of urban roofs and open public space layout of new energy facilities.

(3)We need to use recyclable low carbon environmental protection landscape materials.It includes the landscape treatment of recycled materials and the use of low-carbon environmental protection materials in the landscape.

(4)We should to build low maintenance plant landscape.Including water-saving collocation of native plants and optimization of plant planting methods.

(5) Shaping plant landscape with pollution reduction and noise reduction functions.It includes the use of plants to block noise and reduce the spread of light pollution.

(6) We create a rainwater digestion and utilization system.It includes systematic planning of roof garden, three-dimensional greening and rainwater garden.

\section{Sustainability of Urban Public Space Landscape in Guilin Area}

\subsection{Landscape Space Problem in Public Space}

In Guilin public space,construction land occupies a large number of urban development land, and public space is compressed.The proportion of hard and soft pavement space is out of balance. The main problem is that the pavement area in public space is too large to compress the user space.Generally speaking,for one thing, the pure hard space can bear the high-intensity use of the crowd, but the lack of green space makes public space less comfortable to use.For another thing,too much green planting space and parking space in public space reduce the use area of public space.Public space serves the public.It must be designed according to the needs of potential users around it.Otherwise, it is not a reasonably planned public space.

\subsection{Landscape Energy Consumption in Public Space need to be Reduced}

In Guilin city,the problem of landscape energy consumption in public space is prominent.Landscape night lighting consumes more energy,mainly lighting power.Landscape materials with high energy consumption in the production process are applied in urban public space,such as granite material,ordinary asphalt, ordinary concrete,cement,clay brick.At the same time, the utilization of power generation landscape facilities in public space is insufficient.In order to solve the problem of landscape energy consumption,the use of new energy-saving lamps should be further improved and the lighting scale should be reduced.Landscape materials should conform to the sustainability of ecological environment protection and reduce energy consumption.

\subsection{Planting of Landscape Greening Problem in Public Space}

Plants play an important ecological role in purifying air, beautifying the environment,producing oxygen and negative ions,regulating microclimate,preventing soil erosion,conserving water sources,eliminating noise, sterilizing disease,preventing wind and dust ${ }^{[4]}$. However, in the investigation of plant allocation in Guilin,it was found that plants in public space landscape emphasized beauty rather than environmental benefits.Plants should be used to improve the urban ecological environment, not just to beautify the city. The primary task of plant configuration design should be to solve the urban environmental problems, and then pay attention to the landscape effect,and artistically match the design content to form a better urban style.

\subsection{Digestion and Utilization of Landscape Rainwater Resources in Public Space}

Guilin is located in a low latitude area with a subtropical monsoon climate.It has a mild climate and abundant rainfall.A large amount of rainwater will bring great troubles to the use of urban public space and urban waterlogging.Guilin's public space landscape has relatively low ability to drain and digest precipitation.It can only drain precipitation through drainage infrastructure,which not only makes the city face waterlogging problems, but also has serious security risks.In public space,landscape paving materials should be used more sustainable and ecologically functional materials.

\subsection{Landscape Pollution Reduction and Noise Reduction in Public Space}


In Guilin public space,there are problems of light pollution and noise pollution.Light pollution can be divided into day and night.During the daytime,the sunlight directly shines on the glass facade of the building.Because of the lack of plant shelter at the bottom, the facade will be refracted to the ground to form light pollution.At night,there are a large number of landscape lights arranged for landscape effect in some landscapes. When night falls, there will be "artificial day" situation.Noise pollution manifests itself in the fact that residential and commercial areas are too close to each other and lack of isolation zones.Plant belts can be used as isolation zones to reduce noise.Plant planting density is proportional to plant density ${ }^{[5]}$. Residential areas should form noise protection zones through effective shelter of plant landscape.

\section{Taking Guilin as an Example, the Landscape Regeneration of Sustainable Public Space}

Starting from the key points of sustainable landscape,including energy recycling,material recycling,carbon sequestration and water saving function of plants,rainwater management and recycling system,landscape regeneration design of Guilin City was carried out.

\subsection{Multifunctional Corner Park Design}

In the city,street corner parks are smaller in scale but larger in number.Street corner parks, as the main places of leisure and entertainment for citizens, should focus on reflecting the idea of sustainable urban development.First of all,as a temporary foothold,street corner parks should have the function of multi-function superposition, not only as leisure and entertainment,but also as non-motor vehicle parking areas.Secondly, in plant allocation,we should pay attention to multi-level combination,leave rainwater utilization area in planting pond,and combine with urban irrigation and drainage system.Finally, the landscape pavement should use water-permeable environmental protection materials, and the lighting should also try to use energy-saving lamps with low energy consumption and new energy lighting methods.

\subsection{Roof Garden Design}

In order to reduce the impact of rapid urban development on the ecological environment,many countries in the world have introduced the concept and technology of roof greening,making roof greening a worldwide trend of building greening ${ }^{[6]}$. Roof greening, also known as roof garden,refers to the green space formed by planting flowers and plants on the top of various buildings and building various garden sketches.The dense urban buildings create a good condition for roof gardens, which can be used to achieve good ecological benefits.It is a perfect combination of building space potential and multiple benefits of green plants.First,impermeable materials should be laid on the roof and soil layers should be set up.Secondly, the rainwater is collected and dredged effectively. The surplus rainwater can be digested through drainage pipelines to the ground rainwater garden and grass planting ditch. Then,in the design,plant greening is the main way to avoid using too much hard pavement.Lastly,light media such as perlite and vermiculite should be used in the cultivation medium of plants. The plant types should be selected to adapt to shallow soil and avoid the use of tall trees.

\subsection{Green Design of Building Facade}

Three-dimensional greening is relative to plane greening,mainly using building components and the main structure of the building itself to form a greening way.Nowadays,urban buildings mostly adopt hard and clear materials and simple geometric solid modelling.People inevitably feel monotonous and tedious.Adding plant elements to the facade of buildings can increase the texture of buildings. The building facade integrated with three-dimensional greening cannot only enrich people's visual content, but also beautify the urban street scenery and make the urban space full of vitality.At the same time,buildings covered by three-dimensional greening can reduce the temperature increased by solar irradiation.

In the design of building facade greening,the first thing to do is to unify the style with the greenbelt infrastructure,as well as the architectural space form and facade materials ${ }^{[7]}$. Secondly, the automatic irrigation and drainage system should be designed to estimate the water consumption of plants.Finally,according to the climate and landscape environment of Guilin,the suitable extensive native plants were selected.

\subsection{Planting Design}

Planting design should embody urban characteristics. Firstly, mixed planting plants and different landscape spaces are used to achieve the best landscape effect. Secondly, using seasonal changes, highlighting the different characteristics of different vegetation a year, mainly from leaf, tree, flower elements to create highlights. Finally, native plants are economical and practical, and attention should be paid to the use of native plants.

\subsection{Rainwater Garden System Design}

Using rainwater garden as the cell body of sponge city can provide support for urban ecological construction from bottom to top. Rainwater garden is designed as a whole according to the process of rain retention, infiltration, purification, collection and circulation. The first step is to control the rainwater and to form a rainwater pipeline system from the source to the flow of the accumulated rainwater. The second step is to construct several outdoor small-scale rainwater gardens according to the platform model. The rainwater gardens 
decrease step by step according to the terrain trend. Planting plants with purification effect on each floor of the platform completes the rainwater purification. Rainwater flows through the first platform as primary precipitation, the second as primary purification, the third as secondary purification, and the fourth as tertiary purification, and then enters the stabilization pool. Finally, in terms of the spatial foundation of rainwater digestion system in public space landscape, different forms of treatment are carried out according to buildings and residential districts, green spaces and squares, and roads ${ }^{[8]}$.

\subsection{Nightscape Lighting Design}

The design of night scene lighting system should be carried out from the perspective of urban planning. The current situation of urban night scenery construction is too focused on the point,which makes the integrity of urban night scenery worse.Therefore,in planning and design,we should pay attention to interweaving design and create multi-level night scenery.

Different design strategies should be adopted for different night scene brightening carriers. First of all, the lighting of buildings should have its own characteristics.If it is a modern high-rise building, it can carry out large-scale night lighting design.If it is an ancient building, it should set off the temperament of the building and emphasize the structure of the building. Secondly, in the lighting design of a series of outdoor public places such as parks and squares,people's use needs should be fully considered,and different lighting designs should be carried out according to different needs of users. Then, on the basis of traditional lamps, we should not only satisfy the lighting effect,but also give priority to the use of green and environment-friendly lamps,such as solar lamps,LED lamps and so on.Finally, in the control of night scene brightening, many control modes can be preset in advance, such as weekday mode, Festival mode,energy-saving mode.

\section{Conclusion}

People's living standards are constantly improving.In contrast,environmental pollution and destruction are becoming more and more serious.Sustainable development of the environment is a common problem facing people all over the world. Therefore,cities,as major concentrations of population,must be built with low-carbon,ecological and sustainable urban environment.Landscape regeneration design of urban public space is to apply the theory of sustainable development to urban planning,make the city a place to provide energy and transform waste,realize the recycling of resources, and build an ecological city with low energy consumption.

\section{References}

1. D. Farr. Sustainable Urbanism Urban Design With Nature[M].CABP, 1,6(2013)

2. J. T. Lyle. Regenerative Design for Sustainable Development $[\mathrm{M}]$.TJUP,11,12(2017)

3. L. Li, X. Xu. Studies on Distributed Urban Storm Water Ecological Landscape[J].A \&C,10,103(2014)

4. J. Y. Han. Study on Physiological and Ecological Characteristics and Benefits of Major Landscape Plants in Shenzhen[D].Nanjing Forestry University,(2005)

5. J.N. Liu. Investigation of The Noise Attenuation Function Provided by Landscape Plant[D].Zhejiang university,(2007)

6. G. Wang. Analysis on Greening Landscape Planning of Urban High-density Building Group[J].BS\&T,33,06(2017)

7. T. Tang. Research on Application of Vertical Greening of Residential Building in Guangzhou City[D].Guangzhou university,(2017)

8. Q. L. Song. Low Carbon-an Research of Public Facilities' designing[D].Hubei University of Technology References,(2011) 